\title{
"I" on the Web: Social Penetration Theory Revisited
}

\author{
Dr. Dionysis Panos \\ Department of Communication and Internet Studies \\ Cyprus University of Technology \\ dionysis.panos@cut.ac.cy // dionysis.panos@gmail.com
}

DOI:10.5901/mjss.2014.v5n19p185

\begin{abstract}
This research project aims to highlight how Interpersonal Communication Management Information in Computer-MediatedCommunication has changed over the years, primarily as a result of the widespread adoption of digital practices associated with the Second Internet Age, otherwise called Web 2.0 whichbecame prevalent in the latter part of the 20th century and continues to evolve today. It presents the results of an empirical research project based on data collected longitudinally (spanning the period 2002-2012) from 458 personal semi-constructed in-depth interviews with Internet users from 24 countries. The findings reveal a significant shift in users' perceptions concerning the degree of "security" and "familiarity" of the Web between the pre-and the post- Web 2.0 eras. Additionally, the paper discusses the significant changes brought about with regard to two fundamental concepts in communication theory: the concept of the "audience", and the long-standing dichotomy between the 'private' and 'public' spheres of social life. Based on Social Penetration Theory the paper proposes an integrative model for comprehending the mechanisms of personal information management in interpersonal communication, applicable to both online (Computer-Mediated) and offline (Face-To-Face) contexts of communication.
\end{abstract}

Keywords: Computer-Mediated Interpersonal Communication, Private and Public Personal Information, Self-Disclosure, Social Penetration Theory

\section{Introduction}

Already distanced from the first era of cybercultural studies and its analytical emphasis on the issues of Identity and Community (Reid 1994; Rheingold 1994; Turkle, 1995; Slouka 1995; Argyle \& Shields 1996; Bruckman, 1996; Stone 1996; Robins 1996; Seabrook 1997; Wynn \& Katz 1997; Markham 1998; Wallace 1999; Silver, 2000; Barnes 2001), today we find ourselves in the Second Internet era - often referred to as Web 2.0. - characterized by the ubiquitousness of computing, the practices of produsage, and the dominance of Social Network Sites (SNSs) as the primary mode of mediated social interaction in the digital sphere. Although there is not a definite definition of Web 2.0. ${ }^{1}$, this term is widely taken to signify the move towards a more interactive, collaborative, social and responsive web, related not only to a set of changes in technological standards, but more importantly, to a fundamental change in how we use the Internet and its social affordances. In the early days of the web, we used it as a tool. Today, we are not using the Internet merely as a tool - we are becoming a part of it. As a result of the widespread adoption of highly-interactive applications and platforms amongst internet users (Khang, H., Ki E-J., Ye L., 2012), our relationship with the Medium itself has undergone a major, albeit not always perceptible, change: not only are we increasing our usage of the Internet - from how much time we spend on it at home to how we are increasingly carrying around a version of it in our pocket - but we are changing the way we interact with it. The concepts of a culture of sharing, of ubiquity, hyperconnectivity, and hybridity are today extensively used to describe our mundane online interactions and our everyday encounters with the others who make up our digital personal networks.

The integration of computer-(or mobile)-mediated communication into our daily lives, has changed the symbolic power of technology, turning it into an environment within which almost all of our lifeworld activities transpire, a mediating force whose power is inescapable and holistic (Tapscott, 2009; Wells Brignal III, Van Valey, 2007, boyd, 2008). It could be said that the growth of Web 2.0. technologies has embedded into our daily lives what sociologist Manuel Castells had described

1 The term Web 2.0 was first coined as early as 1999 and was then used by Tim O'Reilly during the O'Reilly Media Web 2.0 conference of 2004 to describe websites that "allow users to interactand collaborate with each other in a social media dialogue as creators of usergenerated content in a virtual community" (O'Reilly, 2005). 
as the culture of "real virtuality", "the enclosing of dominant cultural manifestations in an interactive, electronic hypertext,which becomes the common frame of reference for symbolic processing from all sources andall messages" (Castells, 2000:694). This thrusting evolution of electronically-mediated communication has impacted greatly on all facets of our social and personal lives, including the nature of mediated interpersonal communication, which is the focus of this study.

While the greatest part of research output in the discipline of CMC seems to be focusing on the exploration of the mechanisms of communication in Social Media sites (Wang, et al., 2010; Zywica \& Danowski, 2008) or towards the comparison between different SNSs in terms of their functional and structural features (Kuznekoff J.H., 2013; Shen, Brdiczka, Ruan, 2013), there is a marked absence of approaches that trace and revise how online interpersonal communication over the last decades, and more particularly between what could for analytical reasons be conceptualized as a divide between the pre-and the post-Web 2.0 era. This paper aims to cover this ground by presenting the major findings of a research project that was designed to trace how the attitudes, opinions and behaviours of Internet media users have changed along the transition from the Web 1.0 to the Web 2.0 period. Its dual objective is firstly, to unravel how the mechanics of online interpersonal communication have changed over the years, and secondly, to put forward a revisited model for the theoretical and empirical analysis of how personal information is negotiated and presented in interpersonal communication contexts. It is argued that this model, despite being based on findings from an online research project, is of a wider validity and could be applicable to both mediated and non-mediated contexts of interpersonal communication.

\section{Background}

\subsection{Personal Homepages and Communities}

The appropriation by individuals of the unique affordances provided by Internet-based tools and platforms for the construction of personal identity has been, since the early days of cyberculture, one of the most prolific areas of scholarly research. In the early 1990s, the Internet was touted as a new environment with unlimited potential for identity-management, "laboratory for identity" (Turkle, 1995), the implication being that computer users could play any social role they liked and transform themselves into fantasy selves, free of all physical and natural constraints (Wallace, 1999).

Sociologist's Erving Goffman's dramaturgical theory on self-presentation, impression-management and behavior in public places has been often used to throw light on online identity-construction processes, and continues to be today, in the Second Internet age, a highly influential and helpful interpretative framework for analyzing how identity is performed in digital settings. (Miller, 1995; Walker, 2000; Sherman, 2001; Miller \& Arnold, 2001, (Ross, 2007; Chester \& Bretherton, 2007; Utz, 2010; Pinch, 2010; Tan W.K, Teo H.H., 2011, Cunningham 2013). In the pre-Web 2.0 era, the presentation of the Self (in the sense of making public a personal narrative or description of the Self that answers to the question "who are you?"), was primarily expressed in Personal Homepages, which featured high on the research agenda of cybercultural researchers and digital media scholars (Döring, 2002; Dominick, 1999; Chandler, 1998; Chandler \& Roberts-Young, 1998; Killoran, 2002; Cheung, 2000). In concert with the issue of identity, the topic of community equally captured the sociological imagination in the form of the then newly-emergent phenomenon of "virtual communities" popularized in the works of Howard Rheingold (1994), Smith \& Kollock (1999), Van Dijk (1997), Preece (2000) and others, or related issues of "online collaborative action" (Donelan, Kear, Ramage, 2010) or the "politics of identity" expressed through "virtual ethnicities" and "digital diasporas" (Diamantaki, 2003; Burkhalter, 1999).

\subsection{Self-Presentation as a node of an interpersonal communication network}

Starting in the early ' $00 \mathrm{~s}$, the rapid diffusion of the highly interactive applications of Web 2.0 has provided users not only with the possibility of directly producing, sharing and exchanging multimedia content (textual, video, audio, etc) in a bottomup way (Bruns, 2006; Ochoa \& Duval, 2008, Lastowka, 2007; Van Dijk, 2009; Leung 2009) - thus allowing them to adopt the role of producers in addition to the role of consumers of media content - but has somehow forced them to take a more active role in how they present themselves to others and how they appropriate this self-presentation as a means to connect and form linkages with distant others (Lastowka, 2007; Van Dijk, 2009; Leung 2009). What can be observed as we trace the evolution from the first to the second Internet era, is the gradual shift of focus from digital self-presentation as an end in itself (manifest in the Personal Homepages or in the common interests-based virtual communities), to presentation as a node of an interpersonal communication network, reflecting how our online personal are expressed through social media profiles and interactions. Digital media scholars boyd \& Ellison (2008) argue that SNSs are a type of organizational 
functional extension of virtual communities, citing Facebook as the prime example of a network that evolved from being a bounded, exclusive student network to a rapidly expanding network that spans the globe and encompasses an ever larger part of the demographic. However, by characterizing them as "ego-centered networks" - as opposed to the earlier thematically-organized virtual communities - they position them as an entirely new phenomenon (boyd \& Elisson op.cit:; boyd, 2006), reflecting a growing personalization, self-referentiality and perhaps even solipsism in how communication is enacted in contemporary digital networks. While SNSs do not seem to be easily compatible with the qualitative features associated with "communities" such as boundedness or the existence of a shared public space visible to all members (Rheingold, 1994; 2012; Parks, 2011), they however are no less important given their staggering popularity and their increasing pervasiveness in all dimensions of lived experience and social interaction (boyd \& Elisson op.cit.). Furthermore, networks are heralded as being the mode of social organization that best fits the logic of contemporary society, as in Barry Wellman's (1988) observation that social life is after all made up of networks not closed groups.

The explosive diffusion of SNSs, their ego-centered structure and the new communicational landscape that is now evolving before our eyes, quickly captured scholarly attention oriented towards various different dimensions of digital interaction. Wang, Moon et al (2009), for example, draw attention to the role of visual cues in friendship-formation between Facebook users and highlight the importance of attractiveness of profile photos. Gilpin (2011) has studied the role of Twitter in professional identity and image-construction. Page (2013) compared the narrative structures of YouTube, Twitter and Wikipedia. Paavilainen, Hamari et. al. (2013) have studied the perceptions about social network games, Daraghmi \& Yuan (2014) have confirmed the six degrees of separation theory in Facebook, while Jin (2013) has examined the correlation between loneliness and use of Facebook, finding that while lonely people describe Facebook as an optimal medium for enriching their social lives, they however are left rather unsatisfied from its actual use.

\subsection{Self disclosure}

In thinking how interpersonal communication unfolds online, the concept of Self-disclosure or as Jourard \& Lasakow, (1958, p. 91) phrase it the "process of making the self known to others", has a central role and deserves particular attention. Variables that are examined in studies of self-disclosure are the degree, the breadth, and the quality of the information that is being shared, but probably more important is the process of self-disclosure itself and the subjective meanings attached to it. From the onset of every communicative relationship, the interactants initiate a process of exchanging personal information, whether that is information consciously and strategically given to others or information given-off unintentionally through our verbal or non-verbal behaviours (Goffman, 1959). In effect, the exchange of personal information regulates interaction itself and helps participants negotiate their relationship and interpersonal behaviours (Goffman, 1959). Although the archetypical process of self-disclosure concerns dyadic relations (Laurenceau, Barrett, \& Pietromonaco, 1998; Rubin et. al., 1980), the concept can also apply to groups (Galegher, Sproull \& Kiesler, 1998) or relations with and within organizations (Joinson et. al., 2007).

The process of self-disclosure inherently entails a dimension of risk-taking. Any "request to communicate" extended towards Others, is at the same time a kind of "exposure" (Panos, 2007) as well as an act of taking a risk, given that a failed attempt to communicate may be interpreted as rejection, scorn or even ridicule and castigation. This probably explains why selfdisclosure levels are considerably higher amongst complete strangers (Rubin, 1975), since confiding in strangers rather than friends or acquaintances neutralize the impact of the negative consequences and the risks entailed in self-disclosure. This phenomenon is known in its typical, symbolic form as the "strangers in the train", or the "Strangers on the Internet" (Joinson et. al., 2007), phenomenon, implying the critical role that the factor of anonymity plays in this process. With regards to self-disclosure, studies have showed that the Internet's anonymity ${ }^{1}$ and reduced cues might stimulate online self-disclosure because there is no fear of being ridiculed or rejected (Derlega, Metts, \& Petronio, 1993; Pennebaker, 1989).

\subsection{FTF vs CMC Self-Disclosure and Social Penetration Theory}

\footnotetext{
${ }_{1}^{1}$ Anonymity has been a key research area since the earlier stages of cyberstudies (Turkle, 1995; Barnes 2001; Bruckman 1996; Reid, 1996; Markham, 1998, McKenna \& Bargh, 2000), approached as one of the novel features of CMC, holding both promises and perils for the authenticity of human interaction and self-presentation. The condition of anonymity was construed as having either a liberating effect, in providing individuals with previously unthought of possibilities for unrestrained self-expression (Kiesler, Siegel, \& McGuire, 1984; Kiesler \& Sproull, 1992; Baym, 1998), or a detrimental effect, leading to deindividuation, disinhibition, and even overt hostility due to the reduction in contextualization and social cues available in CMC (e.g. Postmes, Spears and Lea, 1998).
} 
Maybe one of the most debatable research issues of the last two decades in the field of Interpersonal Communication has been whether the process of self-disclosure is more widely practiced in online than in offline contexts of communication. Several theories have been articulated around this question, the most emblematic of which is Walther's Hyperspersonal Model of Interpersonal Communication (1996). In their investigation into the phenomenon of online self-disclosure, Nguyen, Bin \& Campbell (2012) are examining comparatively five of those major theories: (a) the social identity model of deindividuation (SIDE model), (b) the hyperpersonal CMC theory, (c) the reduced cues theory (RCT), (d) the social information processing theory (SIP theory), and (e) the media richness theory (MRT). The researchers reach the conclusion that in effect empirical findings do not seem to support the predominance of one single theory over the others, while at the same time what is manifest is that they overlap to a great extent. As they point out "as it stands, no one theory is correct. In fact, in their own way, each of the five CMC theories presented here are right" (Nguyen, Bin \& Campbell, op. cit. p. 109). This is why they suggest seeking for an "overarching communication theory where communication, mediated or not, is the exchange of information. This theory would account for the role of technology in a way that enables it to be a unified theory of communication rather than theories proposed to explain interactions in either online or offline environment" (op. cit. p. 108).

A single "overarching communication theory" would be useful at least for overcoming the rather pointless analytical distinction between self-disclosure in FTF and self-disclosure in CMC,. So far, basic CMC theories concerning selfdisclosure have been based on the traditional theories concerning FTF communication, the most pertinent of which is Social Penetration Theory. The Social Penetration Theory, a communication and psychology theory credited to psychologists Irwin Altman and Dalmas Taylor (1973), constitutes one of the key theoretical frameworks in the field of Intepersonal Communication and has been applied to contexts as varied as marital and family relations (Honeycutt M. \& Godwin D., 1986), business ethics (Baack, Fogliasso \& Harris, 2000) and management (Baack, 1991). Social Penetration Theory approaches relationship-formation as a dynamic process according to which relationships develop through stages from the most superficial and public to the more intimate and personal. As relationships develop, they penetrate deeper and deeper into private and personal matters, slowing penetrating the communicators' public persona to reach their core personality or sense of self. Persons allow other people to penetrate their public self when they disclose personal information, this making self-disclosure the "vehicle" for transitioning from one relational level to the other. Three basic assumptions entailed in Social Penetration Theory are worth noting:

Firstly, the evolution of a relationship through the different stages does not happen automatically, rather it is the result of individuals acting in a costs and rewards rationale. In other words, the decision to disclose is based on the preceived rewards the person will gain if he or she discloses information. If a person perceives that the cost of disclosing information is greater than the rewards for disclosing information then no information will be disclosed. The larger the reward - cost ratio the more disclosure takes place. It is also the case that more disclosure takes place at the outset of the relationship than at any other stage. Based on such an evaluation of potential costs and rewards, self-disclosure appears to have the characteristics of mutuality and symmetry (balance), while it also tends to increase as the relation evolves (Altman \& Taylor, 1973). It is worth noting that this process of evaluation between costs and rewards while rational and calculative, is not always conscious one. Secondly, the process of self-disclosure is grounded not only in verbal and non-verbal communicative elements, but in every possible environmental factor that may impact on the evolution of the relationship (like time, space and other objective conditions of the environment). Furthermore, self-disclosure is a multidimensional concept that refers simultaneously to the cognitive, emotional and behavioral levels (McCarthy, 2009). Third, self-disclosure has an unmistakably voluntary character and is therefore clearly distinguishable from other related processes, such as selfdescription, which is more public than private (McCarthy, op.cit.), or confession, which entails an element of coercion or revelation as fundamentally non-voluntary processes (Pearce \& Sharp, 1973).

What must be noted is that Altman and Taylor (1973) introduced Social Penetration Theory in relation to one-to-one and face-to-face contexts of communication. On a first look, this classical model does not seem to fit well with CMC and the one-to-many mode of communicating in SNSs (Nguyen, Bin \& Campbell, 2012). However, on a second level, the online environment and $\mathrm{CMC}$ are in fact weaking such distinctions as different modes of interaction (one-to-one, one-to-many) are getting more difficult to distinguish and are happening simultaneously on SNSs. It is of no surprise then that many researchers of human interaction on SNSs have given self-disclosure a central position, thus accepting the position that the process of self-disclosure can be transferred to SNS contexts (McCarthy, 2009; Schouten, 2007; Vitak, 2012; Park, Jin \& Jin, 2011; Nosko, Wood \& Molema, 2010; Palmieri et. al., 2012). In any case, the Social Penetration theoretical framework seems to offer a solid background, not only for an empirical investigation of how Interpersonal Communication and selfdisclosure manifest themselves online, but also, beyond this, a vantage point for formulating a new, integrated theoretical 
model of Interpersonal Communication which transcends the online-offline dichotomy, as Nguyen, Bin \& Campbell have proposed (2012).

\section{Research Study}

\subsection{Research Outline and Purpose}

The research project, the findings of which are presented in this paper, was a longitudinal cyberethnography that "followed" the evolution of self-presentation and technology-led social interaction over a ten-year period (2002-2012). The initial research project covered the period from 2002 to 2005 and its aim was to to explore the processes of online selfpresentation and personal identity-construction through Personal Homepages. During the final stages of this first research period in 2005, the research hypotheses and protocol had to be slightly modified and readjusted to be compatible with the Web 2.0 landscape which was emerging at the time and the newer prevalent trends of social networking, produsage, and the observed shifts in the traditional rules governing social conduct along the public-private divide. The second research period covered the years from 2005 to 2012 and focused on exploring how identity is performed and negotiated primarily on the most popular SNSs (MySpace, Facebook) where Internet-based online interpersonal interaction was predominantly taking place.

The overall aim of this extended research study was to carry out a comparative investigation of how the attitudes, perceptions and behaviors of CMC users have changed from the pre- to the post-Web 2.0 era. The research process was completed in 2012 having "followed" the introduction, growth and increasing predominance of social media and social networking platforms as the main mode of human interaction online. Research findings from the early period (2002-2005) were used as primary material based on the hypotheses of the overall research project, without taking into consideration their analysis as regards the research questions of the initial project. Findings from the the two different research periods (2002-2005 and 2005-2012) were combined and co-examined during the stage of data analysis for the purpose of comparative analysis and triangulation.

\subsection{Research hypotheses}

Undoubtedly, in the current cultural condition in which SNSs are the dominant environment for CMC, certain themes and questions that were central during the pre-Web 2.0 period have either changed or lost their significance. One notable change is the shift from anonymity to nonymity in how Internet users interact online. The previously disembodied communication that characterized the first interpersonal forms of online communication (whether in chat, forums, or multidungeon games) has now been superseded as we have moved into an era of nonymity (the opposite of anonymity) and "real names" policies adopted by major internet players, such as Facebook, Linkedln or Google. While traditional anonymous online settings enabled people to leave behind their job, gender, marriage, age, and so on, the norm in most internet-based environments of sociability today is that of participating with your real, offline identity and making that identify immediately visible to others. In other words, the online identity should outwardly map correctly on to body, gender, location and so on, precisely because it is anchored in relationships that exist in the physical world and thus maintain a variety of socialties. In the nonymous setting of Facebook people are enticed to take all that information that relates to their offline identities and offline connections with them, or as Time Magazine (2010) phrased it: "Facebook makes cyberspace more like the real world: dull but civilized. The masked-ball period of the Internet is ending". This is not to say that in the pre-Web 2.0 period the need for "real identities" and authenticity was non-existent. Personal Homepages were after all an attempt and a means to create spaces where real people's individual identities could be expressed and gain credibility in the eyes of others (Dominick., 1999; Panos, 2007).

Taking such shifts into consideration, the overall research question underlining this project is how the functional logic, creative affordances and narrative structures of Web 2.0 have impacted on users' overall perceptions towards CMC and the Social Web in general. More precisely, three research hypotheses can be formulated:

R. H.1. Internet users' perceptions concerning CMC have considerably changed over the last years, principally as a result of the different affordances (creative, expressive, narrative and technical) provided by Web 2.0 standards and SNSs.

R.H.2. There has been a significant shift in how CMC users perceive of their role both as content-producers and as communicators with other users between the pre- and post-Web 2.0 era. 
R.H.3. There has been a fundamental change in how users negotiate the public-private divide in relation to personal information management in CMC.

The three research hypotheses are based on the fundamental assumption that the complete mediation of our lifeworld by digital technologies is not so much a technological, but a social development with ramifications that impact on multiple facets of our personal and public lives (Katz \& Rice, 2002; Castells, 2001). The advent of Web 2.0 applications and their rapid adoption by an increasingly large and varied part of the global demographic have ushered in the era of the Social Web and have turned the network of networks, that is the Internet, into a persistent structure of our social lives, especially for the generation of the millenials or the so-called "digital natives" - a term that has been used to describe people born during or after the 2000s who have grown up with digital technologies and are therefore highly familiar and comfortable using them in their daily activities (Prensky, 2001; boyd, 2014). Under these conditions, our perceptions of what the Internet is and what Internet users can do has changed considerably.

In their everyday interactions in social networks and platforms of online information-sharing and community, individuals enact many of the archetypical rituals of interpersonal communication, as they are described in for example Erving Goffman's microsociology, arguably the most thorough and insightful theoretical framework for understanding the fundamentals of interpersonal communication. In the goffmanesque universe, the presentation, performance and management of the Self is a key pillar of interpersonal communication, no matter what the communication context is. Also, despite the fact that self-presentation and self-disclosure are distinct terms in reality they coalesce to a large degree, both being part of the "process of making the self known to others" (Jourard \& Lasakow, 1958, p. 91). The voluntary process of self-disclosure can be encapsulated in the answers provided to the following critical questions: "Who are you?" and "How do others see me?" (Hall \& Pennington, 2013) or "Who am I?" and "What matters to me?" (Livingstone, 2008). These processes underline the web of interpersonal associations that are formed online and much of the construction work concerning our digital identities.

Evidently, the issues concerning self-presentation, and more specific questions like whether self-disclosure concerns oneto-one or one-to-many relationality (Nguyen, Bin \& Campbell, 2012, p. 104), are directly related to the traditional notions of the Private and the Public and how the boundaries between them are being redefined in mediated communication (West., Lewis \& Currie, 2009; Lange, 2007; Panos, 2007 p.32). Web 2.0 marks a fundamental change in how we conceptualize and negotiate the Private and the Public divide, a divide that has traditionally regulated how our social lives are organized but is today increasingly loosing its relevance and significance.

\subsection{Research methodology}

In order to explore and answer the above-mentioned questions, a longitudinal, cyberethnographic qualitative research study was implemented, based on semi-constructed in depth personal interviews with Internet users, conducted online, in both synchronous and asynchronous mode. Document analysis, systematic observation and diaries were used as additional data collection methods. Obviously, the objective of exploring and recording the mechanism through which SNS users "declare" their presence online, circulate self-related information and initiate an interaction with others requires an in-depth and long-term perspective, rather than a momentary depiction of the moment (Lindlof, 1995, Marshall \& Rossman, 1999). The complex web of interactions between internet users and their social environment, and most importantly the emic perspective, that is the views of the people involved in the research and their perceptions, meanings and interpretations, can be more fully captured through an approach that is sensitive to subjective meanings and contextualized realities. For this project, the choice of the qualitative form of social inquiry, and ethnography as a key qualitative methodology within the interpretivist paradigm, was evaluated as the most appropriate for the discovery of central themes and for learning from participants in a setting or a process the way they experience it, the meaning they put on it, and how they interpret what they experience. A grounded, ethnographic methodology allows for discovery and does justice to the perceptions and the complexity of the individuals' emic interpretations. Within this approach, richer and more sophisticated data can be collected through the use of online semi-constructed in-depth personal interviews (Baker, 1994; Walsh, 2004; Byrne, 2004).

During the first period of the research project (2002-2005), the sample of participants included Personal Homepage Owners. Such individuals were chosen randomly, after being identified as registered users in four specific Personal Home Page Directories (DMOZ, Soul of the Web, Yahoo, Google). A pilot research conducted prior to the main research with a limited number of users allowed for selection of participants according to three criteria:. a) Overall content of the Home Page can be qualified as "personal" (individual project and not family or group/team Home Page), b) Home Page should contain a "narrative" of the Self (at any kind or form) and c) Its main content language should be English, French, Spanish 
or Greek. In order to meet the above criteria, four types of Personal Homepages were excluded: a) Personal Homepages that revolved around specific themes hobbies, b) Fan Personal Homepages, c) Commercial Personal Homepages and d) Underage Personal Homepages (according to self-reported age by homepage owners themselves).

During the second period of research (2006-2012), participants were again contacted through personal invitation either on their personal blogs, or their SNS (MySpace and Facebook) profiles. The invitees were informed about the research procedure and were asked to provide their consent in order to partifcipate through the various stages of the research project. In both research periods and in order to facilitate the process of finding potential participants, a special website was created with the tile "I on the Web", which included full details concerning the research project, its objectives and its procedures. On the website there was also an electronic consent form which potential participants could complete and directly send to the researcher. The particular form of communication proved to be very useful especially during the first research period, albeit less so in the second period when SNSs allowed for direct communication and a higher level of oneto-one interactivity. English was the main language for the implementation of personal interviews. A number of interviews were carried out in Greek (72), in French (3) and in Spanish (7).

Concearning the data collection, 187 of the interviews were conducted asynchronously, through e-mail exchanges. On average, the full cycle of each asynchronous interview was completed through 10 email message exchanges from both sides. Remaining 298 interviews were conducted synchronously, real-time chat programs were used, primarily ICQ, MSN and a small number of IRC channels during the first period and Google Talk and Facebook Chat during the second research period. In both research periods, the research interview guide remained the same, following the same themes and questions with only slight modifications adjusted to changes in the general CMC environment from the pre-Web 2.0 to post-Web 2.0 era (for example codes for SNS usage, profile photo selection, and friending practices were added in the second research period).

Interviews were transcribed and consequently analyzed by using the technique of Discourse Analysis. Analytic categories were developed through identifying themes and features that recurred in the transcripts, moving from open coding to axial coding and then to selective coding through concept-mapping and abstraction (Kinchin, Streatfield, Hay, 2010; Wheeldon \& Faubert, 2009; Jackson \& Trochim, 2002). After the concept-mapping was completed, seven (7) major thematic codes emerged and formed the backbone of the subsequent analysis. A random selection of $15 \%$ of the total research interviews (actual number $=69$ ), was examined by a second researcher, which resulted in the acceptance of five (5) out of the seven (7) common thematic codes (agreement rate: $71,4 \%$ ).

\subsection{Research Data and Analysis}

During the total duration of the research study, 2754 invitations were sent to potential research participants. There were 1922 refusals or non-answers to the initial invitation. 832 individuals contacted the researcher asking for additional information, clarifications or explanations. 485 interviews were evaluated as valid for data collection (including those who advanced up to a point but were discontinued for various reasons, a problem that emerged entirely during the first research period). A total of 316 interviews were fully completed in both research periods. The response rate calculated based on the number of extended invitations in correlation with the fully-completed valid interviews was $16,6 \%$.

Out of the total 458 interviews, 147 were conducted during the first research period (2002-2005) and 311 were conducted during the second period (2006-2012). Constant communication throughout both periods was maintained with a small number of participants (12). Of the total participants 289 were male and 169 were female. It is worth noting that while males were more or less equally distributed between the two research periods, female participants were unevenly distributed with the majority of them taking part in the second research period. Mean age of research participants was 28.8 (according to self-reported age).

The data that was gathered through document analysis and systematic observation were analyzed and triangulated with data drawn from the individual interviews (Baym N, 2010). All social clues about the participants were taken through selfreport by participants themselves. According to their personal statements, participants were located in 24 countries (Greece 58; Cyprus 14; USA 96; UK 76; Canada 34; Belgium 5; France 4; Germany 14; Sweden 9; Thailand 2; Singapore 1; Australia 29; Russia 16; Romania 1; Egypt 7; Turkey 9; Portugal 5; Zimbabwe 1; India 23; Brazil 7; Italy 10; Japan 18; Spain 8; Finland 7), while 4 participants of the first period (Home Page Owners) refused to reveal their country of origin or location (and their web presence did not include clear cues linking to any one particular country). 
As regards the methodological design, it is also worth noting that the data that emanated from asynchronous interviews was much thicker and richer than the data that was drawn from the asynchronous ones, a finding that corroborates the already empirically-grounded view that the asynchronous mode provides users with the more time, flexibility and comfort resulting in more carefully-crafted and sophisticated responses and messages (Meho, 2005; Kazmer \& Xie, 2008). The asynchronous mode also removes much of the pressure of direct feedback expected in real-time conversation and is thus more favorable to the emergence of a trusting relationship between interviewer and interviewee (Mann \& Stewart, 2000). The largest number of non-responses or rejections in both research periods $(62 \%$, total number $=1191)$ came from individuals who appeared to have a female identity in their Personal Homepages and their SNS profiles.

\subsubsection{Emerged Thematic Codes}

\section{The seven (7) key coded Themes that emerged from the data analysis process were the following:}

\subsubsection{Motives and expectations}

The first Theme concerns the primary motives behind a user's decision to create a personal presence on the Web and the expectations associated with this decision. As far as the first research period is concerned, two observations can be made: first, being a Personal Homepage Owner is considered to be a "personal achievement" due to the "courage", initiative, willingness and effort entailed in setting up and maintaining a personal website. Second, in the first, pre-Web 2.0 era and in relation to Personal Homepages in particular, expectations of human interaction and interpersonal communication with Others were rather low. Research findings also indicate that during the same first period (pro-Web 2.0) specific elements of FTF Interpersonal Communication culture were replicated and reproduced online. Web presence in the Personal Homepage format experienced as a "bounded personal space", in goffmanesque terms a back-stage region or a "territory of the Self' (Goffman, 1971), a preserve that needs to be controlled by the social individual. Concomitantly, it was found that users had a heightened awareness of the issues of personal data and privacy, which were frequently considered as treasures to be vehemently protected from the intrusion of outsiders. Suspicion, mistrust and fear of "intrusion" were frequently-reported emotions, while the Web was often signified as 'an unsafe place' where one should always be on the alert - paradoxically all this while a personal web presence had already been created with the explicit or implicit aim of communicating oneself to the outside world.

On the contrary, data drawn from the second research period (post-Web 2.0) reveal an almost staggering shift from the previously pervasive feelings of unsafety and risk towards equally pervasive and entrenched feelings of nativeness, familiarity and safeness in the online world.. The role that SNSs have played in this perceptual shift cannot be underestimated. Establishing a personal presence on SNSs is no longer considered to be a personal achievement, but a normed and mainstream way of confirming your social existence, your professional and personal identity and your belonging in a nexus of interpersonal relations with others. Today, maintaining a web presence, primarily in the form of social media profiles, is a mundane activity of the contemporary quotidian, a commonplace and ordinary creation, and one that is more "extrovert" than "introvert" given that it emerges as self-presentation addressing a more defined and visible audience, a presence to be continually shared, tagged, updated, linked and paralleled with the stories and personal declarations of the others who make up one's network. Therefore, largely due to the structurally different logic of SNSs, both the motives behind creating a web presence and the expectations attached to it differ considerably between the preand the post-Web 2.0 periods.

P.17 (2003): "No, I wouldn't say that I feel absolutely secure and comfortable when I'm online...I'm always watching my back for dangers"

P. 442 (2010): "Of course I feel safety on the Net, why shouldn't I? We are all doing more or less the same things in there. To be true, I feel safer there than walking on my neighborhood ..."

\subsubsection{Personal Narratives}

The second Theme that emerged from data analysis has to do with personal narratives and how they are being negotiated and constructed online. It is evident from the comparative examination of the technical features of the Personal Homepages of the pre-Web 2.0 era that in order to have a personal web presence the user should spend some considerable time 
acquiring and practicing new media literacy and development skills. In relation to the previous element of personal achievement, Personal Homepages involved a process of creative construction on the part of their owners.

However, even after the advent of Web 2.0. applications and SNSs, certain SNSs - MySpace being the most characteristic - allowed a different creative intervention of the profile page owner. In any case, the creation of a profile in a SNS is a process that is accessible to the average user and one that does not require sophisticated or specialized technical knowledge. Basic Web 2.0 applications changed dramatically the nature of the Internet itself, transforming it from a medium "for the few" into a mass medium "for anyone", whatever the positive or negative consequences of this development. This is the idea behind the discourse about a more "responsive" and "adapted" or "personalized" Web that is characteristic of the Second Internet age. The Web 2.0 ideas of produsage, collaborative creation and social networkinga, in a nutshell the ideas of bringing the power of people into the Internet wouldn't be possible without an appropriate technology to support it. For the collective knowledge of people to be harnessed, and for social networking to be adopted, software platforms must be easy enough to use by the average, non tech-savvy user.

P.432 (2009): "In the early '00s it wasn't a game at all. You should spend a lot of time 'till you succeeded in having your own page. If you didn't know how to do it, you had to learn it"

P.450 (2011): "Everybody is on social media today - and I really mean it ...everybody: from tech-trolls to my grandmother. Literally"

\subsubsection{Selection of self-centered elements}

The third Theme concerns how the individual user selects, manages and presents the constitutive elements of the Web personal presence. To start with, it must be noted that any form of web presence requires at least a minimum of constitutive elements that need to be put together by the acting individual so that a more or less consistent and attractive identity is constructed and projected in the public space. In the pre-Web 2.0 era much more was required by the user, and the resulting personal homepages were much more idiosynchatic and individualized, from a content and aesthetics perspective, compared to let's say current Facebook or Linkedln profiles. However, even in the most strictly structured and uniform SNSs or blogs (based or default, pre-defined read-and-write platforms) there is still ample room for curating the Self and for the creative appropriation (and remix) of communicative and technical elements that will make up one's profile, including the fully-integrated multimedia possibilities (text, image, video, etc) of current social media platforms.

What can also be observed is a significant shift in the rationale behind the selection of what elements to integrate in one's profile. From the carefully-selected and often meticulously-constructed web presence of Personal Homepages, we have moved to a situation where web presence has become a permanently and easily available affordance, a taken-for-granted practice of practically every digital media user, and one that is seamlessly integrated into our daily, always-on, perpetually connected and increasingly mobile lives. Social media practices have literally woven the Internet into our everyday lifeworld milieu, forever merging the previously distinct realms of the online and the offline, or the mediated and the non-mediated. This observation is corroborated by the data drawn comparatively from the first period data which revealed a feeling of distanciation from web presence and a hybrid understanding of our everyday information-and communication practices as online-and-offline at the same time.

P.3 (2002): "Of course l'm not going to put out there the worst of me and I don't really spend much time on it. It is just something I like to do some from time to time during my week - my home page is not my entire life"

P.455 (2011): "I can't imagine not even a single day without checking my FB or Twitt account. It's on my everyday thingsto-do list"

\subsubsection{Audience}

Drawing from Goffman's (1959) dramaturgical perspective of interpersonal communication and taking a web presence to be a "request to communicate", the fourth Theme refers to the real or imagined, visible or invisible audience to which selfpresentation is addressed. In other words, who are the Others to which this call to communicate is extended and how do individual profile owners perceive of this audience and it receives his or her personal statements?

The majority of the Personal Homepage owners were not found to have a very clear knowledge of those who were likely to come across their websites and show interest in their personal stories, neither were they in a position to attribute particular demographic, lifestyle, technical or psychographic characteristics to their possible "audiences". Instead, their 
online self-presentation and the content that they selected and uploaded on their personal site - as well as their request to communicate - seemed to address an unkown "general" audience that had the unspecified characteristics of "the whole Internet population" or at best "those who would share the same interests as me".

On the contrary, SNS profile owners strategically select the members of their networks and are thus more in control of their potential audience, an audience that is no longer invisible and unspecified but nonymous and to a large extent overlapping with and anchored in their offline networks. In fact, the phenomenon of "context collapse" that cyber-anthropologist Michael Wesch (2007) identified as characteristic of interaction in social media platforms, (denoting the phenomena in which new media enables connection with any number of people in different parts of the world at the same time, means that there is no particular context to such interaction unlike everyday interaction and that at any given point we upload information without knowing who will watch it, when, and why) seems to apply more to the pre-Web 2.0 era of Homepages or current blogging and vlogging, rather than the SNSs like Facebook, Linkedln or Twitter which are made up of "friends" and "connections" established initially in the offline world. Those friends and friends of friends, colleagues and acquaintances differ from the largely "imagined" audience of the pre-Web 1.0 Personal Homepages, in that they are more likely to respond to the extended call to communicate, by answering our Facebook mail, commenting on our status update post, or like our more recently uploaded picture. As Burgess and Green point out (Burgess and Green, 2009:54) in their discussion of YouTube blogging, interactive, participatory, but also intimate relationships are built on the fact that "persistent direct address to the viewer inherently invites feedback".

P. 21 (2003): "It is interesting but scary at the same time not knowing who's going to see your homepage. It's out there, "open' for anyone, anytime"

P. 458 (2012): "Oh yes, I definitely want to manage who's having access to my FB page and who's not. I don't want to connect with anybody but only to the people I want to. I can arrange that, through settings"

\subsubsection{Interaction}

The fifth Theme relates to how the communication linkages are established between each profile owner and his or her perceived or actual audience and it centers on issues of modes of address, actual perceptions and the complex web of interactions in the Social Web. The difference between the levels of interaction between the first and second research period are notable. The predominantly text messages that were previously sent directly to Personal Homepage owners by an interested member of the audience who happened to come across the person's homepage are today being replaced by the intricate and multidirectional interactions that flow across the nodes and clusters of contemporary global networks. At the same time, maintaining one's personal network in an SNS (through regular digital practices of liking, tagging, updating, posting, commenting, sharing, etc) is often experienced as a "social obligation" rather than an optional pastime, while feelings of "pressure", "saturation" and "overload" have often been reported by many users who describe themselves as "avid or heavy social media users".

P. 5, (2002): "I like it when a visitor leaves a message on my personal home page. If I don't know them and provided they give me their email address I will always write back to them. I will do that whenever I "am" on my homepage, which is not everyday of course"

P. 440, (2010): "I check my profile every day and in fact, many times throughout the day. I like to know if someone contacted me or made a comment that I have to respond to. I also don't want to miss on something interesting or important that has been shared on my page. This is how Facebook is ...you have to be there a lot to maintain your contacts and relationships....Yes, it is one of the first things I do after I wake and on my way to work...and one of the last things I do before I go to bed..."

\subsubsection{Negotiating the boundary between the "Private" and the "Public"}

The sixth Theme is of critical importance to how we understand Interpersonal Communication in the Web 2.0. It relates to how the "private-public" divide is being reconfigured along the invisible borders of digital connectivity, and how this reconfiguration is involved in the processes of self-presentation and online social interaction. A theme that recurrently came up in the interviews with Perosnal Homepage owners was the experience of feelings of apprehension, skepticism, unwillingness, and even anxiety, towards the prospect of having their personal photos uploaded online in order to give a face to the website and the its textual content. Unquestionably, personal photos are one of the most powerful identifiers in 
the digital realm as they are in the offline world, as well. Online, linking a website, a comment, a profile, a blog, or any kind of user-generated content to a particular personal image photo functions as physical evidence, fixing the subject in the tangible world and evoking a verification of the imminent and concrete individual that is physically absent from CMC. Personal photos are important online in that they impart a "sense of presence", by testifying to the real being of the individual that they portray. Self-created, carefully chosen and edited images act as a indisputable stand-in for the creator's physical Self in an environment where all information is digitally represented and intangible.

Analysis of interview data demonstrate that the majority of the participants of the first research period perceived of the prospect of linking their online personal with a personal photo as a "dilemma", a choice of risk as well as a potential threat to their treasured privacy. In short, it was viewed as some kind of "exposure" of sensitive personal data in what was experienced as an intriguing yet largely threatening new digital universe. In the Web 2.0 era of nonymity and the breakdown of traditional notions of the private and the public (as well as of the online-offline divide) this "fear of being exposed" appears to have been greately mitigated. According to data from September 2013 (Whitepaper 2013) 350 million pictures are being uploaded on Facebook on a daily basis (out of a total of 250 billion pictures or an average of 217 pictures per Facebook user). What was formerly private and personal has now entered the domain of the public, irreversibly annihilating the previously straightforward distinction between the public and the private.

P. 23, (2003): "I decided not to have a photo of mine on my home page. I don't feel that secure - in fact I feel like I'm being naked in the public. What should count is what I say, not what I look like".

P. 456, (2012): "Why not? Everyone's doing it. I don't think about it that much - if I've got a good or a funny picture of me or my friends I upload it immediately. Why shouldn't I?"

\subsubsection{Adgustment}

The seventh Theme Code concerns the strategic and tactical mechanisms of adjusting one's personal webpresence, depending on encountered conditions. The fact that web presence is no longer to be viewed as a static self-presentation but as a perpetually changing central hub for one's web of transitive connections, has created the need for updating the interpretative frameworks we use to deciphere self-presentation online use.

P. 27, (2004): “The Internet is a wonderful thing. For people like me it's like a 'shelter' from reality. But that doesn't mean there are no rules. It is just that you have to learn them".

P. 453, (2011): "I'm old enough to remember the world prior to the Web and the words without cellphones. Although at times I find it difficult to recall what is was or felt like ..."

\section{Discussion}

\subsection{Fundamental changes}

The advent of Web 2.0. and the increasing pervasiveness of digital connectivity has had wide-ranging and profound consequences on how we understand and enact our personal identities in settings of interpersonal and public communication.

Research Hypotheses $1 \& 2$ appears to be verified by the analysis of gathered qualitative data. The widespread adoption and technological advancement of digital technologies in the recent years have not only placed the user into the epicenter of information-sharing and communication, but have also transformed the nature of the Medium itself, making the Internet (now accessible anywhere-anytime thanks to Internet-enabled mobile devices) continuous with daily life itself; no longer a gadget for the few, but a multimediator of every single of our daily activities, an integrated environment that crosses the boundaries between the private and the public, the online and the offline, the virtual and the real, and engulfs us all in the daily rituals of digital connectivity. Connecting with the Internet, and establishing a digital online persona is no longer an exotic hobby, or the exception, but a global norm and a routine habit, making the Internet a highly embedded, even invisible, part of our immediate lifeworld environment (DiNucci, 1999; Deuze, 2012).

"Owning" a personal space during first research period was still considered to be a privilege for the few (those members of the technological elite, who were privileged and passionate enough to develop the required digital skills). This is not the case anymore. The introduction of applications that allow the average user to become "producer and content manager" at the same time, has transformed the Web into a space of "open sociability" and effortless hyperconnectivity. In this new field 
of "open sociability" the features of Interpersonal Communication are different from the pre- Web 2.0 era. As can be drawn from the research material, Facebook largely owes its success to the fact that it "responds" to three key needs of its users: 1) The need to have a "public" space in which individuals can "declare" their presence and gain visibility 2) The need to be able to "connect" our presence to others and create an "intimate environment" and 3) The need to do all the above in more or less the same way, under the same conditions, in a socially and technologically equalizing manner regardless of our levels of technological knowledge or expertise. In fact, self-presentation and the confirmation of one's personality in the eyes of a circle of friends, relative and acquaintances, is what Facebook is quintessentially about. This audience is no longer the faceless, impersonal, generalized and unknown audience of the Personal Homepages of the pre-Web 2.0 era, but a more or less known and identifiable network of our offline contacts, a variety of interconnected audiences selected and defined by the individual and developing around around the individual - hence their description as ego-centered networks of connections one usually knows from the offline world, and to which one is connected with varying degrees of intimacy, and with ties that usually range from the strongest to the weakest. Social Networks in which we maintain an online presence no longer "feel' like an "unknown or unexplored territory". They feel more intimate, and more sociable, populated by an expanding number of "Friends" - a rather loose, even abusive contemporary use of the term - who are everyday performing more or less the same rituals as we do: posting and updating, linking and tagging, sharing and commenting on each others input into the system 1 .

Being surrounded by people we consider as "friends" also seems to minimize the feelings of embarrassment. As we know from Goffman's theory (1959), in every incident of "Self Presentation" our main goal is to avoid embarrassment (to "keep face") and that means we have to feel "safe" when we decide to "expose" ourselves to Others. It makes sense that the danger of embarrassment is greater when the Other is a "Stranger" - but when the Other is a "Friend" this danger is minimized. A sense of intimacy is almost automatically created. It could be said that Facebook and Social Media have almost eliminated our previous "fear of exposure". Our presence on SNSs offers a new medium and platform for the visibility of the Self.

According to the "Stranger on the Train/Internet" phenomenon, this should not be expected to happen. So based on the research findings in relation to Research Hypothesis 3 and the "private"-"public" negotiation, it is not clear if it can be confirmed or rejected. The "Stranger on the Train/Internet" phenomenon, leads us to expect that increased levels of intimacy and the more or less "familiar" audience of SNSs, would reduce the intensity of self-disclosure. However, ourfindings demonstrate the opposite - an increase of self-disclosure and a decrease in the sensation of "unsafety" characterized the total communication environment of SNSs. One possible hypothesis related to this inconsistency, is that levels of self-disclosure increase when there is a perception of "reduced risk" and "increased security". It may be that this perception is derived either from the complete lack of previous information (you do not know the stranger, nor does she/he know you - "Stranger on the Train/Internet"), or excessive knowledge of previous information (it's ok to upload hundreds of personal photos because they all do the same in here - SNSs environment). In any case, in order to have a more clear understanding of this paradox a more focused research is needed.

It is also true that the amount or "personal information" which circulates on Facebook on a daily basis can lead to the phenomenon of "information overload", as well as to increased levels of stress emanating from the amount of information that has to be digested and replied to (Koroleva, Krasnova, Günther, 2010; Kietzmann et. al. 2012). It is not certain that we have either the willingness or the ability to process such vast amounts of personal information circulating online, whether that is directly or indirectly linked to the lives of others.

The main features of Computer-Mediated-Communication (CMC) have fundamentally changed: users today more or less "trust" the environment and feel less suspicious moving through it and sharing personal information with others. Eponymity or Nonymity, rather than Anonymity, is today the norm in our online interactions. Rather than wanting to hide their personal identity by adopting a fake one, SNSs are used as spaces for confirming, enhancing and expanding one's personal identity

\footnotetext{
1 It's true that some terms have lost their previous significance or their "true essence" comparing to offline communication. One of those is the term "Friend", which on Facebook environment can be "just someone who knows, someone I know, etc". The concept of the term "Friend" on Facebook, is more trivial comparing to real life (e.g. a Facebook user has 500 "Friends" on hers/his Profile, but in real life her/his close "social circle" includes no more than 5-10 persons). The well-known "Dunbar's Number" should mentioned too in this conversation. According to British anthropologist and evolutionary psychologist Robin Dunbar $(1992,1998)$ there's a cognitive limit to the number of people one can relate in a stable way. Dunbar suggests that we can (socialy) "groom" and sustain no more than 150 relationships. Unsurprisingly Dunbar's theory testing in SNS's environment is a tempting research subject (Gonçalves, Perra \& Vespignani, 2011) although Dunbar himself in his most recent works seems to have moved slightly towards a social penetration theorylike concept but still suggesting more or less the same number (Sutcliffe, Dunbar, Binder \& Arrow, 2012).
} 
through linkages with people and information. This largely accounts for the increased sense of "safety" and "security" experienced by subjects who participated in the second research period. Moreover, the advent of Web 2.0 and the different roles that those "people formerly known as the audience" seem to adopt (real content producers and managers) seems to impart in internet users a sense of personal empowerment and increased control over their digital practices, as well as their self-presentations and personal profiles. We now have the ability to "choose" or "construct" our audience based on personally defined criteria but also as a response to our offline connections' call to communicate (think of the "add me as a friend" Facebook messages).

SNSs have drastically transformed our understanding and attitudes towards what counts as "private" and "public" in communication. Being on our own personal, familiar and secure spaces (like our room, our office or our home) we tend to believe that this familiarity and security is "transferred" onto our own presence in Social Media, without understanding that our online presence on SNSs is not exactly evolving in a "secure private" space but rather in a "public space" with some specific "private capacities " (which often seem to be threatened by the policies of big internet companies, and the growing commercialization that underlines most of our digital practices).

Another important finding is that although we have reached the upper threshold in "exposing" ourselves in hyperbolic incessant communication, exposure in Interpersonal Communication remains an issue that needs to be tackled, managed and resolved by the acting individual. Communicating and exposing Ourselves in Social Media under a variety of different forms (and in increasingly visual and realistic ways) can guide us to contemplate on the mechanisms by which individuals "regulate" the public exposure of their personal information in blended interpersonal contexts. Much of what has been said so far points to how personal information management has changed over the years. It is this to which we will turn now.

\subsection{An overarching interpersonal communication model based on Social Penetration Theory}

The main idea on which the proposed overarching model of interpersonal communication is based is drawn from the Social Penetration Theory first articulated by Altman \& Taylor in 1973, which has been modified and updated, to be more compatible with the contemporary environment of online human interaction. The key difference to the approach of Social Penetration Theory is that while SPT aims to explore the progress and evolution of a "relationship" by focusing primarily on the emotions experienced during the relationship process, the herein proposed model focuses exclusively on the communicative, transactive aspect of Interpersonal Interaction and in particular on the ways in which personal information is being negotiated and managed, regardless of the emotions experienced at the time. Thus, while Social Penetration Theory is a theory pertaining to the field of Social Psychology, the proposed model lies mainly in the field of Communication Interaction Theory.

According to Symbolic Interaction Theory (as expressed primarily in the classic works of the School of Chicago theorists) one of the most central and fundamental issues in (offline) interpersonal encounters is the emergence of a "definition of the situation" (Goffman, 1959), a commonly-shared agreement of "what is happening here", probably the first act of collective creation by the participants to this encounter. This aim is largely achieved through firstly, the ability to protect the privacy of Personal Information, and, secondly, through the ability to arrive at any given time (consciously or unconsciously) at a personal set of "rules" for regulating the "degree of personal exposure" during a communicative encounter. Figure 1 depicts this mechanism of "exposure adjustment" in settings of interpersonal communication. 


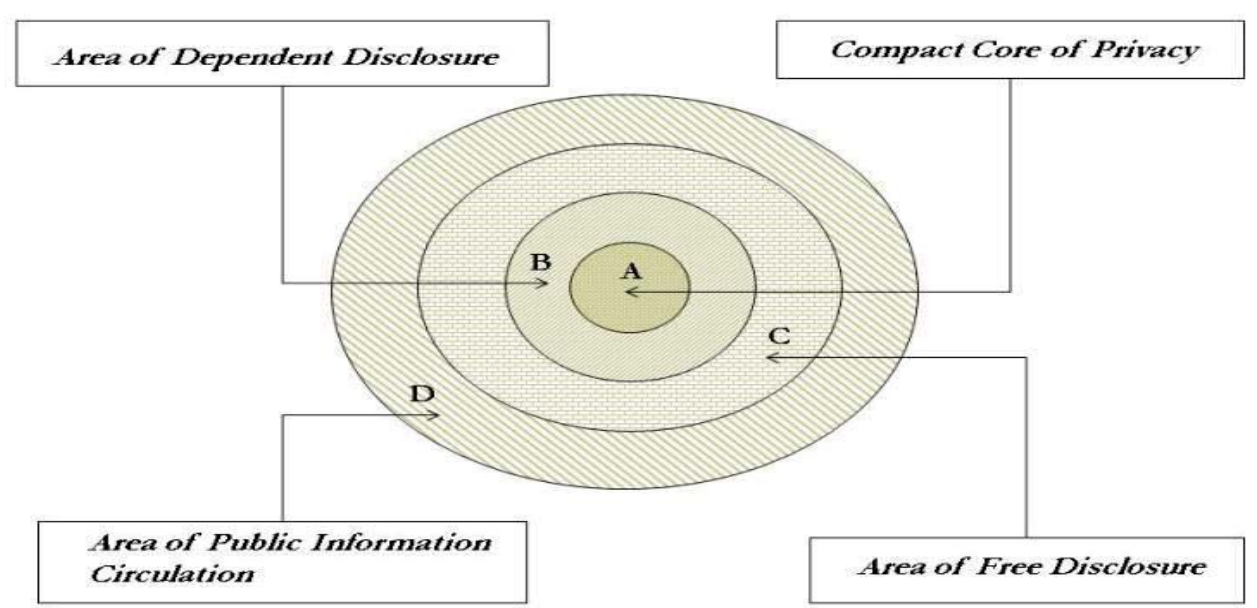

Figure 1. Allocation of the areas of Personal Information

\subsubsection{Compact Core of Privacy}

This inner circle constitutes the "core" of information that is considered to be private and personal. It is the place inhabited by all the "critical" personal information elements (according to our own personal assessment), our very personal existential territory, or our own private and carefully-protected "treasure box". This information may not only relate to information about the Self; it may also include information about the others as well, and all that needs to be shielded, protected, hidden, remain unpublished and invisible from exposure in the public domain. The information residing in this highly private area is viewed by individuals as "secret" or "strictly confidential", and its exposure is often avoided out of the fear of embarrassment, guilt, discomfort, ridicule or criticism from others.

\subsubsection{Area of Dependent Disclosure}

The second circle, named "area of dependent disclosure", corresponds to this area of information about the Self which is considered to be "private" and/or "classified", yet qualifies for publication and can be disclosed without negatively perceived consequences. Information residing in this area can be of two types: firstly, information that is contained in narratives about the Others - the disclosure of which ethnically requires permission from those Others - and secondly, information directly related to the individual, associated with a host of subjective meanings and a potentially wide range of positive or negative emotions. This area hosts "personal information" which usually the individual shares with other persons with whom has a high degree of intimacy.

\subsubsection{Area of Free Disclosure}

Information residing in this third region is considered by the individual to be "safe for disclosure". It is information about the Self that the individual is eager to disclose even to complete Strangers, in order to derive expected benefits. This is the kind of self-centered information that circulates in abundance in social media networks, where in Manovich's words users people "pour as much of their lives as possible" (Manovich, 2009:325) by uploading thousands of their personal photographs and videos and stories and thoughts to share with hundreds of Facebook friends, and revealing intimate details of their daily lives to an expanding number of connections. This region therefore contains all that personal information that is considered to be the proto-material of the archetypical self-presentation in a context of social interaction, and which includes information intentionally given as well as information unintentionally or accidentally given off (Goffman, 1959) 


\subsubsection{Area of Public Information Circulation}

This last and outer circle encompasses all those identity-related elements that constitute already publicly-known information about the Self, attached as it is to the profiles that are publicly visible and available for others to see. While issues of confidentiality, secrecy or privacy are practically irrelevant to this type of information, its role in the presentation of the Self is of critical importance.

\subsection{Overall remarks}

Based on the different areas of self-related information that has been delineated so far, several concluding remarks can be made:

a) The "rules for the regulation of personal exposure" online have to be understood as being context-specific; they differ depending on the environment (the context) as well as on the audience that they address. Moreover, personal identity itself is less about construction and more about performance, reflecting the view that identity is not a singular and stable entity, but rather shifts and changes based on social context and changing communicative needs andd affordances.

b) The areas listed above are not entirely leak-proof or rigidly-fixed; their boundaries are more or less permeable, susceptible to the fluid nature of web interactions. Additionally, the "classification" of Self-related information is perpetually open to change and can easily and seamlessly cross from one region to the other, depending on the situatedness and the particularities of every new incident of interaction.

As fas as CMC is concerned, maintaining a "personal presence" in settings of Interpersonal Communication is essentially about regulating the limits of self-disclosure by "drawing" Personal Information elements from each one of these areas (circles on the graph of Figure 1.). Viewed from that perspective, Web 2.0 and SNSs are not about an entirely new phenomenon. The roots of "social networking" as an abstract concept are to be found in the origins of human society and therefore in the primordial and time-honoured contexts of FTF interaction. Nevertheless, communication in the contemporary digital social networks in which our daily lives are embedded is entirely novel in terms of the previously unthought of scale of connectivity that they enable, as well as in terms of the degree of transparency and public visibility that they impose on our private lives. Self-presentation in the SNSs is no longer a solitary procedure, a staged projection of the public Self as in the Personal Homepages of the Web 1.0. era, but a perpetually emergent, dynamic process of contingent connections with those who make up our digital ego-centered networks of friends and acquaintances. However, given that no one lives solely on the Web, as Kendall (1999) has pointed out, it is important to comprehend the mechanisms of self-adjustment and continuous negotiation of the boundaries of the Self in the increasingly hybrid and pervasive contexts of contemporary sociability. The concept of "rules for the regulation of exposure" in Interpersonal Communication may be helpful in this attempt to throw some light onto the complexities of interpersonal communication online.

\section{Limitations of the research study}

Despite the fact that the total sum of research data produced allowed the comparative analysis of online interpersonal communication between the pre- and the post-Web 2.0 era, this was not the initially-stated objective of the project. The project did not investigate an already existing phenomenon; instead, it traced the evolution of the phenomenon of online social interaction over time and during the last decade that was marked by the transition into the Second Internet age. In that sense, it can be viewed as a project in digital participatory ethnography based on fieldwork and an inductive reasoning in analyzing data. However, the fact that the objectives of the project were slightly modified in the course of the project can be considered to be a methodological limitation. The comparative analysis of collected data was made possible precisely because the data drawn from the second research period and their mode of collection (interview guides, issue prompting, etc) were to a large extent adjusted to the data of the first research period and the initial thematic areas. This notwithstanding, the degree of comparability and data analysis can be evaluated as satisfactory.

On the methodological side, the sample of participants drawn for both the first and the second research period was a convenience sample. Due to the large number of participants and the long duration of the research period, this study cannot be considered a case-study research although ultimately, in a qualitative study, all kinds of "samples" may be viewed as case-studies. The rule of informational saturation was followed, despite the fact that data saturation is hard to determine in online research. In any case, the sample of participants and the purely qualitative methodology that was followed do not allow any quantitative extrapolations. 
The project presented in this paper was based on the qualititative paradigm that was evaluated as being more appropriate for answering the stated research questions (where preemptive reduction of the data would prevent discovery) and for providing access to nuanced information concerning the subjective interpretations and meaning-making processes of individuals engaged in online self-presentation and interpersonal communication.

Given this qualitative research direction, a limitation of the project at hand, and in terms of corpus analysis, may be that its findings cannot be extended to wider populations with the same degree of certainty that a quantitative analysis would allows. This is because the findings of the research are not tested to discover whether they are statistically significant or due to chance. However, it must be noted that the total number of collected data in this research was so large that could be also analyzed through a quantitative methodology, in the hope of producing interesting findings based on statistical inferences. Given that all qualitative data can be coded quantitatively, interview material and extracted codes could be assigned meaningful numerical values which manipulated could help achieve greater insight into the meaning of the data and help examine the specific research hypotheses.

\section{References:}

Altman I., Taylor A., (1973). Social penetration: the development of interpersonal relationships. New York: Holt, Rinehart \& Winston.

Argyle K., Shields R., (1996), Is There a Body in the Net? in Shields R., (Edit.), (1996), Cultures of Internet - Virtual Spaces, Real Histories, Living Bodies, Sage Publications, London - Thousand Oaks - New Delhi.

Baack D., (1991). The Personal Impact of Company Policies: A Social Penetration Theory Perspective. Journal of Managerial Issues, Vol. 3, No. 2 (Summer 1991), p. 196-219. Pittsburg State University

Baack D., Fogliasso C., Harris J., (2000). The Personal Impact of Ethical Decisions: A Social Penetration Theory. Journal of Business Ethics 24: 39-49, 2000. Kluwer Academic Publishers

Baker T.L., (1994). Doing Social Research - Third Edition. Boston, Toronto: McGraw-Hill International Editions

Barnes S., (2001), Online Connections - Internet Interpersonal Relationships, Hampton Press, New Jersey.

Baym, Nancy K. (1998) The Emergence of On-Line Community, in Steven G. Jones (ed.) Cybersociety 2.0.; Revisiting Computer-Mediated Communication and Community. Thousand Oaks, London, New Delhi: SAGE Publications.

Baym N., (2010). What Constitutes Quality in Qualitative Internet Research?. In Markham A., Baym N., (Edit.) Internet Inquiry. Sage Publications.

Boyd d., (2006). Friends, Friendsters, and MySpace Top 8: Writing Community Into Being on Social Network Sites. First Monday 11:12, December.

Boyd d., (2008). How Can Qualitative Internet Researchers Define the Boundaries of Their Projects: A Response to Christine Hine, in Markham A., Baym N., (Edit.) Internet Inquiry: Conversations about Method, pp. 26-32, Sage Los Angeles.

Boyd d., Ellison B.N., (2008). Social Network Sites: Definition, History and Scholarship. Journal of Computer-Mediated Communication, 13 (2008): 210-230. International Communication Association.

Boyd d., (2014). It's complicated - the social lives of networked teens. New Haven+London: Yale University Press.

Bruckman A., (1996). Gender Swapping on the Internet, in Ludlow P., (Edit.), High Noon In the Electronic Frontier Conceptual Issues in Cyberspace, The MIT Press, Cambridge Massachusetts, London, England.

Bruns, A., (2006). Towards Produsage: Futures for User-Led Content Production. In Sudweeks F., Hrachovec H., Ess C., (Edit.), Proceedings Cultural Attitudes towards Communication and Technology 2006, p: 275-284, Tartu, Estonia [Online].Available: http://eprints.qut.edu.au/4863/1/4863_1.pdf (12.5.2014)

Burgess, J. and Green, J. (2009). YouTube: Online Video and Participatory Culture, PolityPress: Cambridge

Burkhalter B., (1999). Reading Race Online: discovering racial identity in Usenet discussions. In Smith A.M., Kollock P., (Edit.), Communities in Cyberspace. Routledge.

Byrne B., (2004). Qualitative Interviewing. In Seale C. (Edit.), Researching Society and Culture. London, Thousand Oaks, New Delhi: Sage Publications 
Castells M., (2000). Toward a Sociology of the Network Society, Contemporary Sociology, Vol.29, No. 5, September 2000, pp.693-699

Castells M., (2001). The Internet Galaxy - Reflections on the Internet, Business and Society. Oxford University Press.

Chandler, D., (1998). Personal Home Pages and the Construction of Identities on the Web [Online] Available: http://www.aber.ac.uk/media/Documents/short/webident.html (2.6.2014)

Chandler, D., Roberts-Young D., (1998). The Construction of Identity in the Personal Homepages of Adolescents [Online]. Available: http://www.aber.ac.uk/media/Documents/short/strasbourg.html (12.5.2014)

Cheung, C. (2000). A Home on the Web: Presentations of Self on Personal Homepages, in Gauntlett, D. (Edit.), Web. Studies - Rewiring media studies for the digital studies. London: Arnold

Chester A., Bretherton D. (2007). Impression Management and Identity Online, in Joinson A., McKenna K., Postmes T., Reips U-D., (Edit). Oxford Handbook of Internet Psychology, p. 223-236. Oxfrod University Press

Cunningham C., (Edit.), (2013). Social Networking and Impression Management, Lexington Books.

Daraghmi Y.E., Yuan S-M., (2014). We are so close, less than 4 degrees separating you and me! Computers in Human Behavior 30, 273-285. Elsevier.

Derlega, V.L., Metts, S., Petronio, S., Margulis, S. T. (1993). Self disclosure. London: Sage.

Deuze M., (2012). Media Life. Polity Press.

Diamantaki K., (2003). Virtual ethnicity and digital diasporas: Identity construction in cyberspace. Global Media Journal American Edition, V.2, I.2, Article No 10 [Online]. Available: http://lass.purduecal.edu/cca/gmi/sp03/graduatesp03/gmjsp03grad-diamandaki.htm (8.6.2014)

DiNucci, D. Fragmented future. Print 1999, 32, 221.

Dominick R.J., (1999). Who Do You Think You Are? Personal Home Pages and Self - Presentation on the World Wide Web, Journalism \& Mass Communication Quarterly, Vol. 76, No 4, Winter 1999: 646 - 658.

Donelan H., Kear K., Ramage M., (2010). Online Communication and collaboration - A Reader. Routledge.

Döring, N. (2002). Personal Home Pages on the Web: A Review of Research. Journal of Computer-Mediated Communication, 7: 0. doi: 10.1111/j.1083-6101.2002.tb00152.x

Dunbar R. (1992). Neocortex size as a constraint on group size in primates. Journal of Human Evolution 22 (6): 469-493.

Dunbar R., (1998). Grooming, Gossip, and the Evolution of Language. Harvard University Press

Galegher, J., Sproull, L., \& Kiesler, S. (1998). Legitimacy, authority and community in electronic support groups. Written Communication, 15, p. 493-530.

Gilpin R.D., (2011). Working the Twittersphere - Microblogging as Professional Identity Construction in Papacharissi Z. (Edit.) A Networked Self, (p. 232-250). New York: Routledge.

Goffman, E. (1959). The Presentation of Self in Everyday Life, Anchor Books Doubleday, New York - London

Goffman, E. (1971). Relations in Public: Microstudies of the Public Order. New York: Basic Books.

Gonçalves B., Perra N., Vespignani A., (2011). Modeling Users' Activity on Twitter Networks: Validation of Dunbar's Number. PLoS ONE 6(8): e22656. doi:10.1371/journal.pone.0022656

Hall J.A., Pennington N., (2013). What You can Really Know about Someone from their Facebook Profile (And Where You Should Look to Find Out). In Cunningham C., (Edit.), (2013). Social Networking and Impression Management, Lexington Books.

Hian, L. B., Chuan, S. L., Trevor, T. M. K., Detenber, B. H. (2004). Getting to Know You: Exploring the Development of Relational Intimacy in Computer-mediated Communication. Journal of Computer-Mediated Communication, 9: 00. doi: 10.1111/j.1083-6101.2004.tb00290.x

Honeycutt M.J., Godwin D.D., (1986). A Model of Marital Functioning Based on an Attraction Paradigm and SocialPenetration Dimensions. Journal of Marriage and Family, Vol. 48, No. 3 (Aug., 1986), pp. 651-667. National Council on Family Relations 
Jackson M.K., Trochim K.M.W., (2002). Concept Mapping as an Alternative Approach for the Analysis of Open-Ended Survey Responses. Organizational Research Methods, Vol. 5 No. 4, October 2002 307-336, DOI: 10.1177/109442802237114

Jin B., (2013). How lonely people use and perceive Facebook, Computers in Human Behavior 29, 2463-2470. Elsevier.

Joinson N.A., Paine C.,Buchanan T., Reips U-D., (2007). Measuring self-disclosure online: Blurring and non-response to sensitive items in web-based surveys, Computers in Human Behavior, doi:10.1016/j.chb.2007.10.005. Elsevier.

Jourard, S. M., Lasakow, P. (1958). Some factors in self-disclosure. Journal of Abnormal and Social Psychology, 56(1), 91-98.

Katz E.J., Rice R., (2002). Social Consequences of Internet Use - Access, Involvement and Interaction. Massachusetts Institute of Technology (MIT Press).

Kazmer M.M., Xie B., (2008). QUALITATIVE INTERVIEWING IN INTERNET STUDIES - Playing with the media, playing with the method. Information, Communication \& Society Vol. 11, No. 2, March 2008, pp. 257-278

Kendall L., (1999). Recontextualizing 'Cyberspace' - Methodological Considerations for On-line Research. In Jones S., (Edit.), Doing Internet Research - Critical Issues and Methods for Examining the Net. Sage Publications.

Khang, H., Ki E-J., Ye L., (2012). Social Media Research in Advertising, Communication, Marketing, and Public Relations, 1997-2010, Journalism \& Mass Communication Quarterly, 89(2) 279-298, Sage Publications

Kiesler, S., Siegel, J., \& McGuire, T. W. (1984). Social psychological aspects of computer-mediated communication. American Psychologist, 39(10), 1123-1134. doi:10.1037/0003-066X.39.10.1123

Kietzmann H.J., Silvestre S.B., McCarthy P.I., Pitt L., (2012). Unpacking the social media phenomenon:towards a research agenda. Journal of Public Affairs (2012). Wiley Online Library, DOI: 10.1002/pa.1412

Killoran J.B., (2002). Private Domains in the Public Domain: The Synthetic Institutionalization of Personal Web Space, Internet Research 3.0 Conference. Maastricht, The Netherlands, 15 October, 2002 [Online]. Available: http://myweb.brooklyn.liu.edu/jkillora/research/2002air.html (2.6.2014)

Kinchin M.I.,Streatfield D., Hay B.D., (2010). Using Concept Mapping to Enchance the Research Interview. International Journal of Qualitative Methods, 2010 9(1), pp.52-68

Koroleva K., Krasnova H., Günther O., (2010). "'STOP SPAMMING ME!' - Exploring Information Overload on Facebook" (2010). AMCIS 2010 Proceedings. Paper 447. http://aisel.aisnet.org/amcis2010/447

Kuznekoff J.H. (2013). Comparing Impression Management Strategies across Social Media Platforms, in Cunningham C., (Edit.), Social Networking and Impression Management, Lexington Books.

Lange, P. G. (2007), Publicly Private and Privately Public: Social Networking on YouTube. Journal of Computer-Mediated Communication, 13: 361-380. doi: 10.1111/j.1083-6101.2007.00400.x

Laurenceau, J. P., Barrett, L. F., \& Pietromonaco, P. R. (1998). Intimacy as an interpersonal process: The importance of self-disclosure, partner disclosure, and perceived partner responsiveness in interpersonal exchanges. Journal of Personality and Social Psychology, 74, 1238-1251.

Lastowka G., (2008). User-generated content and virtual worlds. Vanderbilt Journal Of Entertainment And Technology Law Volume: 10:4, p. 893-917 [Online]. Available: http://www.jetlaw.org/wp-content/journal-pdfs/Lastowka_FINAL.pdf (9.6.2014)

Leung L. (2009). User-generated content on the internet: an examination of gratifications, civic engagement and psychological empowerment. New Media \& Society December 2009 vol. 11 no. 8 1327-1347, Sage Publications

Lindlof T.R., (1995). Qualitative Communication Research Methods. Thousand Oaks, London, New Delhi: Sage Publications.

Livingstone S. (2008). Taking Risky Opportunities in Youthful Content Creation: Teenagers' Use of Social Networking Sites for Intimacy, Privacy and Self-Expression. New Media and Society, 10, no. 3 (2008): 393-411.

Mann C., Stewart F., (2000). Internet Communication and Qualitative Research - A Handbook for Researching Online. Sage Publications. 
Manovich, L. (2009). The Practice of Everyday (Media) Life: From Mass Consumption toMass Cultural Production? Critical Inquiry, Vol. 35, No. 2 (Winter 2009), pp.319-331

Markham A., (1998), Life Online - Researching Real Experience in Virtual Space, Altamira Press, Walnut Creek, London, New Delhi

Marshall C., Rossman G.B., (1999). Designing Qualitative Research. London: Sage Publications

McCarthy A., (2009). Social Penetration Theory, Social Networking and Facebook. [Online]. Available: http://www.anniemccarthy.net/uploads/1/5/0/4/1504159/2009-april-social_penetration_theory_and facebook.pdf (19.6.2014)

McKenna, K. Y. A., \& Bargh, J. A. (2000). Plan 9 from cyberspace: The implications of the Internet for personality and social psychology. Personality and Social Psychology Review, 4(1), 57-75.

Meho I.L., (2006). E-Mail Interviewing in Qualitative Research: A Methodological Discussion. Journal of the American Society for Information Society and Technology, 57(10):1284-1295, 2006

Miller H., (1995). The Presentation of Self in Electronic Life: Goffman on the Internet, Paper presented at Embodied Knowledge and Virtual Space Conference Goldsmiths' College, University of London, June 1995, [Online]. Available: http://www.dourish.com/classes/ics234cw04/miller2.pdf (26.5.2014)

Miller H., Arnold J. (2001). Self in Web Home Pages: Gender, Identity and Power in Cyberspace, in Riva G., Galimberti C., (Edit.), Towards CyberPsychology: Mind, Cognitions and Society in the Internet Age, IOS Press, Amsterdam, p. 73-94.

Nguyen M., Bin Y.S., Campbell A., (2012). Comparing Online and Offline Self-Disclosure: A Systematic Review. Cyberpsychology, Behavior and Social Networking. Volume 15, Number 2, 2012, p. 103-111. Mary Ann Liebert, Inc., DOI: 10.1089/cyber.2011.0277

Nosko A., Wood E., Molema S., (2010). All about me: Disclosure in online social networking profiles: The case of FACEBOOK. Computers in Human Behavior 26 (2010) 406-418. Elsevier.

O'Reilly T., (2004). What Is Web 2.0 - Design Patterns and Business Models for the Next Generation of Software. [Online] Available: http://oreilly.com/web2/archive/what-is-web-20.html (22.6.2014)

Ochoa X., Duval E., (2008). Quantitative analysis of user-generated content on the web, Proceedings of webevolve2008: web science workshop at WWW2008 p:1-8 [Online]. Available: https://lirias.kuleuven.be/bitstream/123456789/200042/1/webevolve2008-03.pdf (29.5.2014)

Paavilainen J., Hamari J., Stenros J., Kinnunen J. (2013). Social Network Games: Players' Perspectives. Simulation \& Gaming, 44(6) 794-820 SAGE Publications

Page R. (2013). Seriality and Storytelling in Social Media. StoryWorlds: A Journal of Narrative Studies, Volume 5, 2013, p. 31-54. University of Nebraska.

Palmieri C., Prestano K., Gandley R., Overton E., Zhang Q., (2012). The Facebook Phenomenon: Online Self-Disclosure and Uncertainty Reduction, China Media Research. 2012; 8(1): 48-53. Edmondson Intercultural Enterprises

Panos D., (2007). The "Trials of Identity" in the Transitional In-Between Area of the Personal Homepages on the Internet In M. Kontochristou (Edit.), Identity and Media on Contemporary Greece, Papazisis Publications.

Papacharissi Z., (Edit.) (2011). A Networked Self - Identity, Community and Culture on Social Network Sites. New York: Routledge

Park N., Jin B., Jin A.S-A., (2011). Effects of self-disclosure on relational intimacy in Facebook. Computers in Human Behavior 27 (2011) 1974-1983. Elsevier.

Parks R.M., (2011). Social Network Sites as Virtual Communities in Papacharissi Z., (Edit.) A Networked Self - Identity, Community and Culture on Social Network Sites. New York: Routledge

Pearce, W. B. and Sharp, S. M. (1973), Self-Disclosing Communication. Journal of Communication, 23: 409-425. doi: 10.1111/j.1460-2466.1973.tb00958.x.. Wiley.

Pennebaker, J. W. (1989). Confession, inhibition, and disease. In L. Berkowitz (Ed.), Advances in experimental social psychology (pp. 211-244). New York: Academic Press. 
Pinch T., (2010). The Invisible Technologies of Goffman's Sociology From the Merry-Go-Round to the Internet. Technology and Culture, V. 51:2, p. 409-424. The Johns Hopkins University Press

Postmes, T., Spears, R., \& Lea, M. (1998). Breaching or building social boundaries? SIDE-effects of computer-mediated communication. Communication Research, 25, 689-715.

Preece J., (2000). Online Communities - Supporting Sociability, Designing Usability, John Wiley and Sons Ltd

Prensky M., (2001). Digital Natives, Digital Immigrants. On the Horizon 9 (5): 1-6.

Reid M.E., (1996), Text-based Virtual Realities: Identity and the Cyborg Body, in Ludlow P., (Edit.), High Noon In the Electronic Frontier - Conceptual Issues in Cyberspace, The MIT Press, Cambridge Massachusetts, London, England.

Rheingold H. (1994), The Virtual Community - Finding Connection in a Computerized World, Minerva Paperback 1995, Great Britain.

Rheingold H. (2012). Net Smart - How to thrive online. MIT Press.

Robins K., (1996), Cyberspace and the World We Live In, in Featherstone M., Burrows R., (Edit.), (1996) Cyberspace I Cyberbodies / Cyberpunk, Sage Publications, London-Thousand Oaks-New Delhi

Ross D.A.R., (2007).Backstage with the Knowledge Boys and Girls: Goffman and Distributed Agency in an Organic Online Community, Organization Studies 2007 28(03): 307-325, Sage Publications

Rubin, Z. (1975). Disclosing oneself to a stranger: Reciprocity and its limits. Journal of Experimental Social Psychology, 11(3), 233-260.

Rubin Z., Hill T.C., Letitia Anne Peplau A.L., Dunkel-Schetter C., (1980). Self-Disclosure in Dating Couples: Sex Roles and the Ethic of Openness, Journal of Marriage and Family Vol. 42, No. 2, p. 305-317, National Council on Family Relations

Schouten A.P., (2007). Adolescents' online self-disclosure and self-presentation. [Online]. Available: http://www.alexanderschouten.nl/thesis_aschouten.pdf (17.6.2014)

Seabrook J., (1997), Deeper: A Two-Year Odyssey in Cyberspace, Faber \& Faber Ltd., New York.

Shen J., Brdiczka O., Ruan Y. (2013). A comparison study of user behavior on Facebook and Gmail, Computers in Human Behavior 29 (2013) 2650-2655, Elsevier Ltd.

Sherman R.C., (2001). The Mind's Eye in Cyberspace: Online Perceptions of Self and Others, in Riva G., Galimberti C., (Edit.), Towards CyberPsychology: Mind, Cognitions and Society in the Internet Age, IOS Press, Amsterdam, p. 53-72

Silver D., (2000), Looking Backwards, Looking Forwards: Cyberculture Studies 1990-2000», in Gauntlett D.A., (Edit.) Web. Studies - Rewiring media studies for the digital age, Arnold, London.

Slouka M., (1995), War of the Worlds - The Assault to Reality, Abacus, London.

Smith A.M., Kollock P., (1999). Communities in Cyberspace. London: Routledge

Stone A.R., (1996), The War of Desire and Technology at the End of the Mechanical Age, MIT Press, Cambridge Massachusetts.

Sutcliffe, A., Dunbar, R., Binder, J., Arrow, H., (2012). Relationships and the social brain: Integrating psychological and evolutionary perspectives. British Journal of Psychology, 103: 149-168. doi: 10.1111/j.2044-8295.2011.02061.x

Tan W-K., Teo H-H., (2011). Impact of Blog Design Features on Blogging Satisfaction: An Impression Management Persective, in Ozok A.A, Zaphiris P., (Edit.) Online Communities, HCH 2011, LNCS 6778: 130-139, Springer-Verlag, Berlin Heidelberg

Tapscott D., (2009). Grown Up Digital: how the net generation is changing your world. Original edition copyright by Don Tapscott.

Time Magazine, Mark Zuckerberg, by Lev Grossmman. Wednesday, Dec. 15, 2010 [Online]. Available: http://content.time.com/time/specials/packages/article/0,28804,2036683_2037183_2037185,00.html (23.6.2014)

Turkle S., (1995), Life on the Screen - Identity in the Age of Internet, Simon \& Schuster, New York. 
Utz S., (2010). Show me your friends and I will tell you what type of person you are: How one's profile, number of friends and type of friends influence impression formation on social network sites, Journal of Computer-Mediated Communication 15 (2010): 314-335, International Communication Association

Walker K., (2000). "It's Difficult to Hide it": The Presentation of Self on Internet Home Pages, Qualitative Sociology, Vol. 23, No 1, p. 99-120, Human Science Press, Inc.

Wallace P., (1999), The Psychology of the Internet, Cambridge University Press.

Walther B.J., (1996). Computer-Mediated Communication: Impresonal, interpersonal and Hyperpersonal Intreaction. Communication Research, 1996; 23; 3. Sage.

Wang, S.S., Moon S., Hazel Kwon K., Evans C.A., Stefanone M.A. (2010). Face off: Implications of visual cues on initiating friendship on Facebook, Computers in Human Behavior 26 (2010) 226-234, Esevier Ltd.

Walsh D., (2004). Doing Ethnograophy. In Seale C. (Edit.), Researching Society and Culture. London, Thousand Oaks, New Delhi: Sage Publications

Wellman B., (1988). Structural analysis: From method and metaphor to theory and substance, as quoted in boyd d., Ellison B.N., (2008). Social Network Sites: Definition, History and Scholarship. Journal of Computer-Mediated Communication, 13 (2008): 210-230. International Communication Association.

Wells Brignal III T., Van Valey T., (2005), The impact of Internet Communications on social interaction, Sociological Spectrum, 25:3, 335-348, Rutledge.

Wesch M., (2007). The Machine is Us/ing Us (Final Version). [Online video project]. Available: https://www.youtube.com/watch?v=NLIGopyXT_g (26.5.2014)

West A., Lewis J., Currie P., (2009). Students' Facebook 'friends': public and private spheres. Journal of Youth Studies Vol. 12, No. 6, December 2009, 615-627

Wheeldon J., Faubert J., (2009). Framing Experience: Concept Maps, Mind Maps,and Data Collection in Qualitative Research. International Journal of Qualitative Methods 2009, 8930, pp. 68-83

Whitepaper from Facebook, Ericsson and Qualcomm, (2013). A Focus on Efficiency. September 16, 2013. [Online]. Available: $\quad$ https://fbcdn-dragon-a.akamaihd.net/hphotos-ak-prn1/851575_520797877991079_393255490_n.pdf (4.6.2014)

Wynn E., Katz J. (1997), Hyperbole over Cyberspace: Self-Presentation and Social Boundaries in Internet Home Pages and Discourse, The Information Society: An International Journal, Vol. 13, No. 4, 297-328, Taylor \& Francis Group.

Van Dijk J.A.G.M. (1997). The Reality of Virtual Community. Trends in Communication, 1 (1). pp. 39-63.

Van Dijk J.A.G.M. (2009). Users like you? Theorizing agency in user-generated content. Media, Culture \& Society, Vol. 31(1): 41-58, Sage Publications.

Vitak J., (2012). The Impact of Context Collapse and Privacy on Social Network Site Disclosures. Journal of Broadcasting \& Electronic Media 56(4), 2012, pp. 451-470

Zywica J., Danowski J., (2008). The Faces of Facebookers: Investigating Social Enchancement and Social Compensation Hypotheses; Predicting Facebook and Offline Popularity from Sociability and Self-Esteem, and Mapping the Meanings of Popularity with Semantic Networks, Journal of Computer Mediated Communication 14 (2008) 1-34, International Communication Association. 